\title{
MEASURING THE ECONOMIC IMPACTS OF REDUCING ENVIRONMENTALLY DAMAGING PRODUCTION ACTIVITIES
}

\author{
Paul B. Siegel and Thomas G. Johnson*
}

\begin{abstract}
The joint production of desirable economic goods and undesirable environmental by-products is not uncommon. An expedient means of reducing undesirable by-products is to reduce production of the desired good. This paper addresses the use of input-output models for analyzing the economic impacts of environmental programs that intentionally reduce output and compensate some economic agents for associated income and employment losses. The objective of this paper is to specify some basic principles that are essential for the economic impact analysis of such programs when using input-ouput models and to demonstrate how neglect of these principles may lead to ambiguous results for policy analysis.
\end{abstract}

\section{INTRODUCTION}

The joint production of desirable economic goods and undesirable environmental by-products is not uncommon. An expedient means of reducing undesirable by-products is to reduce production of the desired good. That is, in such cases, prevention of environmentally damaging production is preferred to treatment of the damage. Increasingly, environmental programs of this nature are being designed, particularly for production activities characterized by limited technological opportunities to reduce the proportion of undesirable to desirable output, high enforcement costs to guarantee adoption of altemative technologies, and high cleanup costs or irreversible damage caused by undesirable by-products. Examples of such programs include the Conservation Reserve Program (1985 Farm Bill), Wetlands Reserve Program (1990 Farm Bill), selected provisions of the Endangered Species Act of 1973 and subsequent updates (e.g., Critical Habitat Designation for the Northern Spotted Owl in 1992), and selected provisions of the Pollution Prevention Act of 1990 (CEQ 1992).

Environmental programs that require reductions in existing levels of economic activity are based on either voluntary or mandatory participation of producers. Some of the programs are designed to compensate producers in some way for losses associated with reductions in output. Such programs recognize a producer's property rights to existing levels of desirable and undesirable output

*The authors are Assistant Professor, Department of Agricultural Economics and Rural Sociology, University of Temnessee, Knoxville, and Professor, Department of Agricultural Economics, Virginia Tech, Blacksburg. 
and, in effect, purchase those rights. In retum, the producer refrains from environmentally damaging production. While the economic impact of reduced production and the payment (or non-payment) of compensation are not the primary objectives of such programs, they nevertheless are of interest to a wide variety of parties and may influence the level of support for (and opposition to) the program.

This paper addresses issues related to the analysis of economic impacts of environmental programs that require reductions in existing levels of desirable output to reduce the generation of undesirable by-products. Attention is focused on the differentiation between: (1) intended and unintended, (2) compensated and uncompensated, and (3) directly and indirectly attributable economic impacts. The objectives of this paper are to specify some basic principles that are essential for the appropriate measurement of economic impacts of such programs when using input-output models and to demonstrate how neglect of these principles may lead to ambiguous results for policy analysis.

\section{ECONOMIC IMPACT ANALYSIS USING INPUT-OUTPUT MODELS}

Input-output models are the most frequently used analytical framework for economic impact analysis. Input-output is a simple general equilibrium approach based on an accounting system of intersectoral purchases and sales. Input-output analysis assumes that each sector purchases factors of production from other sectors and then sells its output to other sectors and/or final consumers. The standard formulation of an input-output model for $n$ sectors is:

$$
X=(I-A)^{-1} F,
$$

where $\mathrm{X}$ is a $n x l$ vector of gross output, $\mathrm{A}$ is an $n x n$ matrix of input-output coefficients, $(\mathrm{I}-\mathrm{A})^{-1}$ is a matrix of multipliers, and $\mathrm{F}$ is a $n x l$ vector of final demand. Assuming fixed proportion production functions, no input substitution, homogeneous sector output, no resource constraints, and frictionless adjustments (i.e., constant returns to scale and fixed prices), economic impacts can be measured in terms of the changes in sectoral gross output resulting from changes in sectoral final demand:

$$
\Delta X=(I-A)^{-1} \Delta F .
$$

Economic impacts can also be measured in terms of changes in sectoral employment and income resulting from changes in sectoral final demand. It is 
possible to calculate employment and income impacts using employment and income coefficients that map a linear correspondence with sectoral gross output:

$$
\Delta L=S \Delta X=S(I-A)^{-1} \Delta F,
$$

and

$$
\Delta Y=W S \Delta X=W S(I-A)^{-1} \Delta F,
$$

where $\mathrm{L}$ and $\mathrm{Y}$ are $n x l$ vectors of sectoral employment and income, respectively, $\mathrm{S}$ is a $n \times n$ diagonal matrix of sectoral employment-output coefficients, and $\mathrm{W}$ is a $n \times n$ diagonal matrix of sectoral income-employment coefficients. Changes in total gross output, total employment, and total income are the respective sums of sectoral changes over $n$ sectors.

In input-output analysis, economic impacts are measured for a given region. Economic impacts that take place outside the region of reference are called leakages and are excluded when calculating regional economic impacts. Economic impacts can be divided into: direct economic impacts-gross revenues received by producers for final purchases of goods and services by consumers, government, and exports; indirect economic impacts-expenditures on factors of production, backward-linkages to input supply sectors affected by the direct economic impacts; and induced economic impacts-subsequent impacts resulting from income received by economic agents during the direct and indirect impacts that are, in turn, spent on other goods and services. By convention, Type I multipliers measure direct plus indirect economic impacts, and Type II multipliers measure direct, indirect, and induced impacts.

Input-output models are often used to measure the regional economic impacts of increased or decreased gross output, employment, and income resulting from policy-induced changes in final demand in a target sector. The objective of many government programs is to increase output, employment, and income by stimulating increases in final demand. Export enhancement programs are examples of such programs. From a regional perspective, increases in final demand resulting from an export enhancement program are reflected in increased gross output, employment, and income. In contrast, environmentally motivated changes in final demand frequently result in reduced economic activity by certain firms or sectors. Under these circumstances, reductions in final demand are reflected in reduced gross output, employment, and income. In some cases, environmentally motivated programs might include compensation to economic agents who are negatively affected by the reduced economic activity. Special attention must be taken in the application of input-output models to the economic analysis of environmental programs that require reductions in final demand, especially in cases when compensation is provided for selected economic agents. 


\section{BASIC PRINCIPLES}

The typical concem of those interested in the economic impacts of environmental programs that require reductions in production is the degree (if any) to which the regional economy is impaired by the program. Sometimes policymakers are interested in knowing which sectors and groups of individuals will benefit from the program and which will bear the costs. An associated concem is with the adequacy of the compensation, if any.

In order to accurately measure the economic impacts of these programs, especially when input-output models are being used, three basic principles should be adhered to.

1. There is a need to differentiate between intended and unintended economic impacts of the program on the target sector and economically linked sectors.

2. There is a need to differentiate between compensated and uncompensated economic losses in the targeted sector and the economically linked sectors.

3. There is a need to differentiate between economic impacts both directly and indirectly attributable to the program.

When using input-output models to measure the economic impacts of reduced production, an analyst has the choice of introducing a change in either the level of final demand in the target sector or the final demand for inputs purchased by the target sector from backward-linked input-supply sectors. The second approach excludes direct effects on gross output, employment and income in the target sector, while the first approach includes them in the first-round effects.

By reducing final demand in the target sector (the first approach), the economic impact analysis includes employment losses of compensated (if any) and uncompensated economic agents in the target sector. In contrast, by reducing final demand in backward-linked input-supply sectors, the economic impact analysis excludes impacts on uncompensated economic agents in the target sector. In both cases, unintended economic impacts on uncompensated economic agents in backward-linked sectors are included (since the input-output model, by design, measures indirect impacts). To introduce a change in final demand for products from forward-linked sectors, the forward-linked sector would need to be considered a target (i.e., producing) sector.

When providing compensation to certain economic agents, the economic impact analysis should include both the receipt of compensation payments and subsequent economic activity generated by the spending of these payments. Compensation payments are intended economic impacts that offset income (and 
employment) losses incurred by economic agents due to planned reductions in economic activity. These payments are usually made to producers with a recognized property right to produce desired and undesired output but could conceivably be made to other economic agents negatively impacted by the program. Use of an input-output model can help identify economic agents negatively impacted by the program. Subsequent expenditures of the compensation payments may offset some of the income (and employment) losses by uncompensated economic agents in the target sector (due to intended economic impacts) and in economically linked sectors (due to unintended economic impacts).

It is, however, important to recall that when measuring sectoral economic impacts, the actual impacts on firms or individuals are not considered. For example, some retail stores will lose business from reduced production in the target sector, while other retail stores gain business from increases in economic activity in other sectors.

Since it is the objective of the program to reduce economic activity in the targeted sector, intended reductions in gross output in the target sector should be differentiated from reductions in gross output (which is the sum of intended and unintended economic impacts). An additional observation about economic impact analyses of this type is in order. Gross output measures the total value of all economic transactions and is a standard result from the input-output model, because data used to construct an input-output model are gross sales data (Shaffer 1989,282 ). However, gross output is not necessarily a useful measure of regional economic well-being. Gross output incorporates double counting of sectoral value added and is sensitive to the level of sectoral and regional aggregation (Miller and Blair 1985, 10). Even though no particular regional economic welfare function is specified, regional employment and income impacts are preferable (albeit partial) measures of economic well-being (Shaffer 1989, 90). Other measures of economic, fiscal, social, and environmental well-being can be calculated based on their relationship to sectoral gross output, as employment and income impacts were calculated in Equations (3) and (4) (Miller and Blair 1985; Shaffer 1989). However, gross output, in and of itself, is not an indicator of well-being.

\section{APPLYING THE BASIC PRINCIPLES TO CALCULATE ECONOMIC IMPACTS OF THE CONSERVATION RESERVE PROGRAM (CRP)}

An existing government program with environmental quality objectives that rewards reduced economic activity and provides compensation for negatively impacted producers is the Conservation Reserve Program (CRP). The CRP was es- 
tablished under the 1985 Farm Bill and extended by the 1990 Farm Bill. The 1990 Farm Bill also established a Wetlands Reserve Program, which is patterned after the CRP (CEQ 1992). The CRP is an acreage set-aside program under which farmers are paid not to produce crops on highly erodible soils. Crop production on highly erodible soils leads to environmental damage associated with soil erosion and downstream pollution (Ribaudo 1989; USDA 1989). The national objective is to enroll 45 million acres in the CRP. By mid-1992, 35.4 million acres were enrolled (USDA 1992).

Farmers voluntarily participate in the CRP by signing a 10-year, no-use rental contract with the United States Department of Agriculture (USDA). The rental payment is set by a bidding process, so that farmers should, in theory, receive at least full compensation for income accruing to their labor, management, and capital that were previously used for crop production. There are no legal restrictions on the utilization of compensated farmer labor, management, and capital and no provisions for compensation to hired farm labor or to economically linked producers and laborers.

From the perspective of economic impact analysis, the critical features that set the CRP apart from more traditional government programs are that the program purposefully reduces output of the target sector and compensates some losers but not others. These features require special attention when analyzing economic impacts of the CRP. In the following numerical example and discussion, the basic principles are applied to an economic impact analysis of the CRP for the Commonwealth of Virginia. The numerical example and discussion are also relevant to similar environmental programs in which the main features, purposeful reduction of output and partial compensation, are present.

Several economic impact studies of the CRP have used the Forest Service's IMPLAN input-output model, Version 2.0. They include Martin et al. (1988), Broomhall and Johnson (1990), Hyberg et al. (1991), and Siegel and Johnson (1991). The IMPLAN model is a standard input-output model that follows the notation and assumptions presented with Equations (1) to (4). The IMPLAN model's database consists of a national technology matrix of sectoral production functions that describe intersectoral purchases and sales and social accounts that describe payments to and expenditures by households (Palmer et al. 1985). The IMPLAN model includes 528 sectors that can be disaggregated to the county level. Since IMPLAN Version 2.0 is based on input-output ratios from 1982, when applying the model all prices must be converted into 1982 prices.

For this economic impact analysis of the CRP with IMPLAN 2.0, a statewide aggregation of Virginia's counties is used. The following economic impact analysis is not as detailed as previous studies; instead, it is used to demonstrate the importance of the basic principles outlined previously. 
The economic impacts of the CRP can be divided into two major parts-those related to reduced crop production and those related to the compensation payments to farmers.

\section{Reduced Crop Production}

Changes in final demand can be considered either by introducing changes in gross revenues directly to the crop production sectors (like Hyberg et al. 1991) or by allocating changes in the crop production sector's purchases from the backward-linked input-supply sectors (like Broomhall and Johnson 1990). When done correctly, these two approaches are identical in their treatment of all subsequent rounds of impacts (i.e., indirect and induced impacts)-only the gross output, employment, and income impacts in the target sector (i.e., direct impacts) are different. In the following example, the first approach was used. The second approach excludes economic impacts on the target sector, thus underestimating negative impacts of the program.

Previous economic impact studies of the CRP included expenditures on the establishment and/or maintenance of vegetative cover. Expenditures on vegetative cover, which are relatively small, are not included in this example.

\section{Compensation Payments to Farmers}

Losses in net farm income resulting from reduced crop production are implicitly a part of the previous example. CRP payments from the USDA are intended to compensate farmers for income foregone from crop production. It was assumed that farm households allocate this income to consumption and saving in a manner similar to income generated from crop production. It was assumed that farmers save 10 percent of this income. Farm household consumption expenditures were allocated to the appropriate goods and service sectors using average consumption patterns in the IMPLAN input-output model.

The following analysis was based on crop production and farm household data for a representative farm in Virginia that produces crops on highly erodible soil. It was assumed that gross revenues per acre of crop production were $\$ 200$, based on a composite acre consisting of com, soybean, and wheat using yield and price data from 1982 to 1987 (Ligon et al. 1988). The average CRP rental payment was assumed to be $\$ 53 /$ acre (USDA 1992). Based on crop budgets, it was assumed that 75 percent of employment in crop production was supplied by farmers, and the remaining 25 percent was supplied by hired labor. The Type II multipliers used in this study are presented in Table 1. 
By mid-1992, about 80,000 acres had been contracted to the CRP in Virginia (USDA 1992). The estimated statewide economic impacts of enrolling 80,000 acres in the CRP with an annual CRP payment of \$53/acre are given in the SUBTOTAL row of Table 2 . The estimated impacts include declines in total gross output and total income of $\$ 19,200,000$ and $\$ 7,040,000$, respectively, and a decline of 176 jobs. The findings reported by Hyberg et al. (1991) are comparable to the

TABLE 1

Output, Employment, and Income Multipliers

\begin{tabular}{lcc}
\hline \hline Multipliers & Crop Production & $\begin{array}{c}\text { Farm Household } \\
\text { Expenditures }\end{array}$ \\
\hline $\begin{array}{c}\text { Total gross output multiplier } \\
\text { (\$ total gross output } \\
\text { per } \$ 1 \text { final demand) }\end{array}$ & 1.55 & \\
$\begin{array}{c}\text { Employment multiplier } \\
\text { (\# of jobs per } \$ 1,000,000 \\
\text { final demand) }\end{array}$ & 19.5 & \\
$\begin{array}{l}\text { Income coefficient } \\
\text { (\$ income per } \\
\$ 1 \text { final demand) }\end{array}$ & 0.62 & 20.5 \\
\hline
\end{tabular}

SUBTOTAL economic impacts in Table 2. The SUBTOTALS in Table 2 indicate the actual changes in regional economic levels, but not necessarily the relevant changes from a policy perspective.

It is important to explain the adjustments made to proceed from the SUBTOTAL to TOTAL economic impacts in Table 2 . The SUBTOTAL indicates a decline of 176 jobs from 80,000 acres enrolled in the CRP. Since, when modelling the economic impacts, the CRP was introduced as a reduction in final demand in the crop production sectors, the SUBTOTAL decline in employment includes all on-farm labor. However, farmers who voluntarily enroll in the CRP are essentially being paid not to produce. Their reduced employment can be considered a compensated farm employment reduction and differentiated from total employment losses. Compensated farm employment losses were calculated as follows:

Thirteen of 19.5 jobs per $\$ 1,000,000$ of final demand for crop production were on-farm labor, and it was assumed that 75 percent of on-farm labor was by the farmer. So, $120=[(13 \times 0.75) / 19.5] \mathrm{x}$ $240]$, where the decrease in employment in the crop production sec- 
TABLE 2

Economic Impacts of the CRP Based on 80,000 Acres

\begin{tabular}{|c|c|c|c|c|c|}
\hline & & $\begin{array}{l}\text { Change in } \\
\text { Final } \\
\text { Demand } \\
(\$)\end{array}$ & $\begin{array}{c}\text { Impact on } \\
\text { Total Gross } \\
\text { Output } \\
\text { (\$) }\end{array}$ & $\begin{array}{c}\text { Impact on } \\
\text { Employ- } \\
\text { ment } \\
\text { (\# of jobs) }\end{array}$ & $\begin{array}{c}\text { Impact } \\
\text { on } \\
\text { Income } \\
(\$)\end{array}$ \\
\hline A. & $\begin{array}{l}\text { Reduced crop } \\
\text { production }\end{array}$ & $-16,000,000$ & $-24,800,000$ & -240 & $-9,920,000$ \\
\hline \multirow[t]{2}{*}{ B. } & $\begin{array}{l}\text { Farm household } \\
\text { expenditures }\end{array}$ & $+3,840,000$ & $+5,600,000$ & +64 & $+2,880,000$ \\
\hline & $\begin{array}{l}\text { SUBTOTAL } \\
(\mathbf{a}+\mathbf{b})\end{array}$ & & $-19,200,000$ & -176 & $-7,040,000$ \\
\hline C. & $\begin{array}{l}\text { Compensated } \\
\text { Employment } \\
\text { Losses }\end{array}$ & & & +120 & \\
\hline D. & $\begin{array}{l}\text { Compensation } \\
\text { payment to } \\
\text { farmers }\end{array}$ & & & & $+4,240,000$ \\
\hline E. & $\begin{array}{l}\text { Intended } \\
\text { reduction in } \\
\text { target sector }\end{array}$ & & $+16,000,000$ & & \\
\hline & $\begin{array}{l}\text { TOTAL } \\
(a+b+c+d+e)\end{array}$ & & $-3,200,000$ & -56 & $-2,800,000$ \\
\hline
\end{tabular}

tor was calculated to be 240 in row (A) of Table 2.

In contrast, since there is no compensation paid to displaced hired farm labor or displaced nonfarm labor in backward-linked sectors, their employment losses are included in the TOTAL negative employment impacts of the CRP. As the TOTAL row of Table 2 indicates, after this adjustment, there is a smaller negative employment impact resulting from the CRP.

The indirect impact of increased CRP payments on income is the income generated in the regional economy by the farm household expenditures of CRP payments $(\$ 2,880,000$ in row (B) of Table 2$)$. However, since the change was introduced as a vector of changes in household expenditures, the SUBTOTAL economic impact on income does not include the initial (direct) CRP compensa- 
tion payment from the USDA. Since CRP payments are originally received by farmers as a compensation payment, this direct income impact should be included in the calculation of TOTAL economic impacts as in row (D) of Table 2. As the TOTAL row of Table 2 indicates, after this adjustment, there is a smaller negative income impact resulting from the CRP.

As Table 2 indicates, the SUBTOTAL economic impact of the CRP on total gross output in the regional economy is relatively high-about $\$ 19$ million. However, since it is the program's objective to reduce output in the target sector, when measuring regional economic impacts, an adjustment should be made to differentiate between intended and unintended reductions in target sector output. In this case, the unintended reduction in total gross output was $\$ 8,800,000(\$ 24,800,000$ $-\$ 16,000,000$ )-the indirect and induced total gross output impacts. The gross output impacts resulting from the infusion of farm household expenditures offset this reduction by $\$ 5,600,000$, so that TOTAL negative impacts on gross output were $\$ 3,200,000$. However, as explained previously, policymakers should not pay too much attention to gross output impacts, adjusted or unadjusted.

The analysis of economic impacts can be extended to design an environmental program that reduces target sector production but is neutral with respect to regional employment or income impacts. It is possible to find the appropriate compensation payment (or other new sources of final demand) that would lead to zero values in total employment and/or income impacts (last row of Table 2). This type of breakeven approach, which was used by Siegel and Johnson (1991), is the reverse of the input-output model presented in Equations (3) and (4). In this case, negative changes in $\mathrm{L}$ and $\mathrm{Y}$ are known, and the offsetting level of positive changes in $\mathrm{F}$ is calculated.

As Table 2 shows, adjustments made in accordance with the basic principles can make an important difference in the interpretation of a program's regional economic impacts. In this case, without the suggested adjustments, negative economic impacts of the program could have been overestimated. Analysts should provide policymakers with information on both the adjusted and unadjusted employment and income impacts so policymakers can decide on the relevant basis for evaluating the program.

The economic impact analysis presented in Table 2 is limited in scope because it focuses attention on changes in employment and income that are directly attributable to the CRP. These results are abstractions that measure the instantaneous economic impacts of the CRP and explicitly exclude any adjustments that might occur over time (Hyberg et al. 1991). In reality, structural adjustments will take place over time as resources are reallocated, new resources are identified, and prices change. These structural adjustments are the indirectly attributable economic impacts of the program. The standard input-output model requires addi- 
tional information and assumptions about changes in $\mathrm{F},(\mathrm{I}-\mathrm{A})^{-1}, \mathrm{~S}$, and $\mathrm{W}$ to measure economic impacts associated with structural adjustments. In many cases, additional information and assumptions about changes in prices, technology, and trade are required, which, in turn, requires complex models of economic behavior by households, firms, sectors, and regions. Because of the range and complexity of these assumptions, a single estimate is unlikely to be accurate, and different studies can provide a wide disparity of results (GAO 1990).

Previous studies have pointed out that there are some indirectly attributable economic impacts of the CRP. Except for legal restrictions, once economic agents in the target sector reduce their level of output, they are free to transfer idled resources to other economic activities. Despite the absence of such restrictions, this and previous economic impact studies of the CRP do not account for transfers of idled labor, management, and capital resources to on-farm or off-farm activities. If the farmer transfers idled resources to other on-farm activities, the program's objectives of reduced crop production and associated environmental damage might indeed be compromised. If, on the other hand, the farmer transfers labor to off-farm activities, there will be no impact on the program's objectives, because total regional employment (last row in Table 2) would not change unless there was some new source of final demand. That is, in the absence of some new source of economic activity, the farmer would replace an existing member of the labor force. Economic impact analysis based on the standard input-output model presented in Equations (1) to (4) is a demand-driven model of a regional economy where excess capacity of productive resources is assumed to exist. Within the standard input-output model framework, there is no mechanism for the transfer of productive resources, that is, unless it is assumed that the economy is operating at full capacity and there is some existing source of excess final demand, or there is some new source of final demand. Thus, information and assumptions about projected changes in final demand are required to model the transfer of resources.

Improved environmental quality might result in increased productivity of some sectors and increased demand for the goods and services of other sectors. For example, decreased soil erosion and downstream pollution can result in higher productivity of water purification plants and increase the demand for recreational activities (Ribaudo et al. 1989). Improvements in environmental quality might lead to ancillary impacts on other sectors that result in increased productivity and/or increased demand. Increased economic activity in sectors benefitting from improved environmental quality might lessen the negative impacts resulting from reduced output in the target sector, especially if labor is highly mobile between sectors. Once again, additional information and assumptions are required to model these structural adjustments. 
Reductions in target sector output might impact forward-linked sectors. In this and previous economic impact studies of the CRP, only economic impacts on backward-linked sectors were explicitly considered. As pointed out previously, to introduce a change in final demand for products from forward-linked sectors, the forward-linked sector would be considered the target (i.e., producing) sector. It is possible that the reduction in output will result in higher prices for the remaining output from the target sector. Indeed, supply control (and higher producer prices) is a secondary objective of the CRP (USDA 1989). The higher price for agricultural output could have a negative economic impact on sectors that market and process agricultural products and other sectors that use agricultural products as inputs. However, the standard input-output model is a fixed-price model. Hence, projected price changes and impacts on technology, demand, and trade need to be explicitly incorporated into the input-output model.

Previous studies of economic impacts of the CRP cited in this paper have not attempted to model the indirectly attributable economic impacts of the CRP. In all cases, these indirectly attributable economic impacts and their anticipated effects were discussed, but no attempt was made to explicitly model them and include them in the economic impact analysis. This is in contrast to some recent studies of the economic impacts of critical habitat designation for the northem spotted owl, another environmental program that requires reductions of existing levels of production to prevent undesirable outcomes.

\section{ECONOMIC IMPACT ANALYSIS OF CRITICAL HABITAT DESIGNATION OF THE NORTHERN SPOTTED OWL: SOME OBSERVATIONS}

Based on the Endangered Species Act of 1973, the northern spotted owl was listed as a threatened species in July 1990 . It was decided that the way to prevent extinction of the northern spotted owl was to preserve its natural habitat by reducing timber harvests in old-growth forests. In January 1992, about 7 million acres in the Pacific Northwest (Oregon, Washington, and California) were designated as critical habitat, and timber harvests were strictly regulated. There has been a great deal of concern over the economic impacts of reduced timber harvests in the Pacific Northwest (CEQ 1992). Provision of compensation payments to economic agents negatively impacted by the program have been debated, but no procedure for compensation has been adopted.

The IMPLAN input-output model has been used in several studies of economic impacts of the northern spotted owl, with a wide disparity in projected employment and income impacts (Stevens 1991; Sample and Le Master 1992). 
Stevens (1991) and Sample and Le Master (1992) compare and critique several studies, the results of which have been used by the Department of Interior and U.S. Congress to assess the economic and environmental impacts of the critical habitat designation (Federal Register 1992). It is important to point out that the wide disparity in results, from 12,000 to 147,000 jobs lost, is a major reason that the issue of compensation payments has been placed in limbo.

Much of the disparity in projected economic impacts is due to differences in assumptions related to the three basic principles presented in this paper. Sample and Le Master $(1992,33)$ point out that it is important to "focus on the changes in harvest levels and employment directly attributable to old-growth habitat protection." Some studies claim that the timber sector and economically linked sectors are in secular decline so that negative economic impacts should be downsized. Other studies assume that increased timber harvests outside designated critical habitat areas might maintain existing levels of regional employment and income. These assumptions are based on a structural adjustment process that has both temporal and spatial dimensions.

To date there is no provision for compensation payments to economic agents negatively impacted by the program. However, there has been some discussion of possible compensation payments for private landowners and job retraining programs for loggers and laborers in timber-related sectors. Furthermore, it is hoped that economic diversity in some regions may lessen the impact of projected declines in employment and income because it "provides a broad base of employment" (U.S. Department of Interior 1992, 55). However, as pointed out previously, unless there is some new source of final demand in regions negatively impacted by restrictions on timber harvests, new jobs will not be created. The new sources of final demand can come from compensation payments to negatively impacted economic agents or programs specifically geared at enhancing regional economic activity. Job retraining programs are an indirect method of enhancing economic activity; they take time to be effective and require new sources of final demand to generate new jobs.

The studies also vary greatly in their assumptions about timber prices, responses by private landowners to higher lumber prices, timber imports and exports, and "related economic reactions that might tend to either mitigate or to aggravate the loss of jobs in the Pacific Northwest" (Stevens 1991, 1). The studies have made different assumptions about changes in the supply and demand of timber, timber products, production technologies, etc. These assumptions are highly speculative and require complex models to generate estimates. Sample and Le Master $(1992,34)$ conclude that "when the varying assumptions used in the studies are made explicit and understandable, policymakers and the public should 
find it easier to reach conclusions about the possible employment consequences of various options..."

These observations about economic impact studies of critical habitat designation of the northern spotted owl are not intended to be comprehensive. Instead, these observations do provide some evidence to support the claim that more attention to basic principles is needed when applying standard input-output models to the analysis of environmental programs that intentionally reduce existing levels of regional economic activity.

\section{CONCLUSIONS}

This paper points out the need to devote special attention to basic principles when using an input-output model to analyze the economic impacts of environmental programs designed to reduce existing levels of output, notably programs that compensate some, but not all, economic agents for reductions in economic activity.

This type of program is not uncommon. As policymakers increasingly direct their attention to environmental programs that protect natural resources (e.g., air, water, and land resources) and endangered species by reducing selected economic activities, such analyses will become even more common. This paper provides a basis for approaching an economic impact analysis of trade-offs inherent in such programs.

The following are specific recommendations when using input-output models for economic impact analyses of environmental programs that involve intentional reductions of economic activity with or without compensation of some economic agents:

1. Employment impacts should differentiate between employment losses of compensated (non-compensated) economic agents. It is important to identify any economic agents who are compensated for losses so that negative economic impacts are not inflated.

2. Income impacts should include both the initial impact of the compensation payment and the secondary impacts that result from the spending of the compensation payment. Income impacts affecting noncompensated economic agents are considered separately.

3. For programs based on reductions in existing levels of output, the measurement of changes in gross output should differentiate between intended reductions in the target sector and unintended reductions in economically linked sectors. 
4. Even though gross output is a standard result of input-output models, it should not serve as a basis for comparison among alternatives. For policy analysis, appropriate measures of economic welfare such as employment and income should be considered.

5. The possible transfer of compensated idle resources to other economic activities should be considered but modelled with special care. In some cases, producers might be compensated for reduced production and still be allowed to maintain their productive assets. If there are no legal restrictions on altemative economic utilization of these resources, it is important to know if they are being employed elsewhere as a supplement or replacement for other labor, management, or capital resources. The measurement of potential economic impacts from such resource transfers should be differentiated from economic impacts directly attributable to the program.

6. It is important to consider the potential economic impacts on forwardlinked sectors that are impacted by reduced economic activity in the target sector and on sectors not economically linked to the target sector that might benefit from improvements in environmental quality. On the one hand, reductions in undesirable output may result in higher prices for desirable output from the target sector. On the other hand, improved environmental quality might result in increased productivity and/or increased demand in sectors that benefit from improved environmental quality. The measurement of potential economic impacts from forwardlinked sectors and subsequent improvements in environmental quality should be differentiated from economic impacts directly attributable to the program.

7. Distributional issues regarding individuals and firms should be considered. Environmental programs based on reduced output do not generally provide compensation for losses to all economic agents in the target sector or in sectors economically linked to the target sector. Depending on the distribution of property rights and/or political power, different individuals and firms can command different levels of compensation. Furthermore, since improvements in environmental quality might result in increased productivity and/or demand in other sectors not economically linked to the target sectors, it is important to identify winners and losers in such programs. Finally, it is important to recall that overall economic impacts on a sector do not reflect actual impacts on firms or individuals. For example, individuals or firms might lose business from reduced production in the target sector, while others gain business from increases in economic activity in other sectors. 


\section{REFERENCES}

Alward, G. A. "IMPLAN Version 2.0: Methods Used to Construct the 1982 Regional Economic Data Base." Fort Collins, Colo.: U.S. Forest Service, Draft.

Broomhall, D. E., and T. G. Johnson. "The Impact of the Conservation Reserve Program on a Region in Rural Eastem Georgia." Review of Regional Studies 20, no. 2 (Spring 1990): 66-75.

Council on Environmental Quality (CEQ). Environmental Quality. 22nd Annual Report. Washington, D.C., March 1992.

Federal Register. "Endangered and Threatened Wildlife and Plants: Determination of Critical Habitat for the Northem Spotted Owl: Final Rule." Fish and Wildlife Service, Department of the Interior. January 15, 1992.

Government Accounting Office (GAO). "Conservation Reserve Program: Determining Program's Effects on Production Depends on Assumptions."

No. B-240174. Washington, D.C.: Resources, Community, and Economic Development Division, July 1990.

Hyberg, B. T., M. R. Dicks, and T. Hebert. "Economic Impacts of the

Conservation Reserve Program on Rural Economies." Review of Regional Studies 21, no. 1 (Spring 1991): 91-105

Ligon, P. C., S. S. Batie, W. R. Kerns, D. B. Taylor, and P. B. Siegel. "Chesapeake Bay Farmers' Participation in the Conservation Reserve Program." Staff Paper SP-88-10. Department of Agricultural Economics, Virginia Tech, Blacksburg, May 1988.

Martin, M., H. Radtke, B. Eleveld, and S. D. Nofziger. "The Impacts of the Conservation Reserve Program on Rural Communities: The Case of Three Oregon Counties." Western Journal of Agricultural Economics 13, no. 2 (December 1988): 225-232.

Miller, R. E., and P. D. Blair. Input-Output Analysis: Foundations and Extensions

Prentice Hall, Inc.: Englewood Cliffs, New Jersey, 1985.

Ribaudo, M. O., S. Piper, G. D. Schaible, L. L. Langner, and D. Colacicco. "CRP: What Benefits?" Journal of Soil and Water Conservation 44, no. 5 (September-October 1989): 421-424.

Sample, V. A., and D. C. Le Master. "Economic Effects of Northem Spotted Owl Protection: An Examination of Four Studies." Journal of Forestry (August 1992).

Shaffer, R. Community Economics: Economic Structure and Change in Smaller Communities. Ames: Iowa State Press, 1989. 
Siegel, P. B., and T. G. Johnson. "Break-even Analysis of the Conservation Reserve Program: The Virginia Case." Land Economics 67, no. 4 (November 1991): 447-461.

Stevens, B. H. "Final Report on the Comparative Evaluation of Two Major Studies on the Employment Impacts of the ISC Northern Spotted Owl Conservation Strategy on Washington, Oregon, and California." Technical Bulletin No. 91-11. American Forest Resource Alliance, Washington, D.C., 1991.

United States Department of Agriculture (USDA). Conservation Reserve Program: Progress Report and Preliminary Evaluation of the First Two Years. Washington, D.C., January 1989. "Conservation Reserve Program, Logo-Package: Includes Eleventh Signup Results." Washington, D.C., Agricultural Stabilization and Conservation Service, July 1992.

United States Department of Interior (U.S. Interior). Economic Analysis of Critical Habitat Designation Effects for the Northern Spotted Owl. Washington, D.C.: U.S. Fish and Wildlife Service, January 1992. 